RESEARCH REPORT

\title{
Nonagenarians and centenarians in Switzerland, 1860- 2001: a demographic analysis
}

\author{
Jean-Marie Robine, Fred Paccaud
}

J Epidemiol Community Health 2005;59:31-37. doi: 10.1136/jech.2003.018663

See end of article for authors' affiliations

Correspondence to

Professor F Paccaud,

IUMSP, Bugnon 17,

$\mathrm{CH}-1005$ Lausanne

Switzerland; Fred.

Paccaud@inst.hospvd.ch

Accepted for publication 26 March 2004
Study objective: To explore the rapid rise of the extremely old population, showing the magnitude of the increase and indentifying demographic mechanisms underlying this increase.

Design: Demographic analysis using census data, yearly population estimates, and mortality statistics. Setting: Switzerland 1860-2001.

Main results: Indicators suggest a strong increase in the number of nonagenarians and centenarians in Switzerland as compared with other countries. The increase is mostly attributable to the decline in mortality after age 80 . This decline started in the 1950s.

Conclusion: Nonagenarians and centenarians constitute a new population, which became sizeable after 1950 in Switzerland. There is a need to monitor this population with appropriate demographic and epidemiological indicators.
W orldwide, life expectancy at birth $\left(\mathrm{LE}_{[0]}\right)$ has more than doubled over the past two centuries, increasing from 25 to 65 years for men and to 70 years for women in developed countries. ${ }^{1}$ In some industrialised countries, $\mathrm{LE}_{[0]}$ for women has increased by three months per year for 160 years. ${ }^{2}$ Current values of $\mathrm{LE}_{[0]}$ in Switzerland are 77.2 (men) and 82.8 (women). ${ }^{3}$ As noted by Oeppen and Vaupel, ${ }^{2}$ if the current trends are to continue in the future, $\mathrm{LE}_{[0]}$ will reach 100 in about six decades.

One consequence is the rapid increase in the number of nonagenarians, centenarians, and supercentenarians. ${ }^{4}$ Such an increase is particularly impressive in North America, Europe, ${ }^{67}$ or Japan, ${ }^{8-10}$ where the number of centenarians has been doubling every 10 years since the 1960 s. $^{4}$

Although the public health implications of increased longevity are widely recognised, ${ }^{11}{ }^{12}$ substantial efforts have still to be made to reach a better understanding of the dynamics of increase in the population of the oldest old. ${ }^{13-20}$

In this perspective, the magnitude and rate of increase in the population aged 90 or more have been explored in Switzerland since 1860. Furthermore, the demographic mechanisms underlying this increase have been investigated. Relative to other European countries, Switzerland has suffered less from major disasters, such as war, over the past 150 years. Although this uniqueness may limit the generalisability of the results, it allows for observation of a long series of demographic data on longevity.

\section{POPULATION AND METHODS}

Given the exploratory nature of the analysis, classic demographic indicators and new longevity indicators have been used to measure the prevalence of population at extreme age (from census data and intercensus estimates) and its mortality (mainly through life expectancy).

Decennial censuses, conducted at the beginning of December every 10 years since 1860 (an exception was 1940, replaced by a census in 1941), provide direct counts of people by age year.

Yearly estimates of the population counts have been available since 1860, every 31 December, up to the age of 99 years (that is, a single category includes people aged 99 and more).
The centenarian doubling time is the number of years needed to double the number of people aged 100 and more in a community; it is calculated from the annual increase in the absolute number of centenarians.

Life expectancy (LE) has been computed from period life tables-that is, as a composite indicator summarising the mortality rates at a given time. Period LE describes the survival pattern of a fictitious cohort of people experiencing at all ages the mortality rates observed during this period in the population. LE is computed as the number of years lived by $l_{x+1}$ people at age $x$, plus half a year lived by $l_{x}-l_{x+1}$ people (to take into account the fact that a person lives on average half a year in the year of death); the total amount of lived years is then divided by the number of people at age $\mathrm{x}$.

The centenarian rate $(\mathrm{CR})$ is an estimate of the "production" of centenarians by a population. It is the number of survivors aged 100 at a given date divided by the size of the corresponding cohort at a given age, for example, a cohort at birth $\left(\mathrm{CR}_{[0]}\right)$, at 80 years $\left(\mathrm{CR}_{[80]}\right)$, etc. For example $\mathrm{CR}_{[60]}$ is the number of centenarians produced by the people alive 40 years before (that is, when they were aged 60 years).

The number of deaths for people aged 100 and more has been available in Switzerland since 1940. ${ }^{321} 22$

The mortality of centenarians has been estimated by dividing the number of deaths at age 100 by the census estimate of the number of people aged exactly 100 years at the census.

Census counts, intercensus estimates, and vital statistics have been made available by the Swiss Federal Office of Statistics (SFOS) via existing publications. ${ }^{23-25}$

\section{RESULTS}

Figure 1 shows the secular change in life expectancy for the period 1876-2001. Apart from a substantial decrease in $1918^{*},{ }^{26-28}$ life expectancy at birth $\left(\mathrm{LE}_{[0]}\right)$ increased by $98 \%$ for

\section{Abbreviations: $L E$, life expectancy; $C R$, centenarian rate; $C D T$, centenarian doubling rate}

*Influenza devastated Switzerland in 1918 with a two peak epidemic (July, then October to November); about $58 \%$ of the population was infected; the estimated number of deaths was 20000 , most of them in the age range 20 to 50 years, out of a population of 3.9 millions (as of 1 January 1918). 


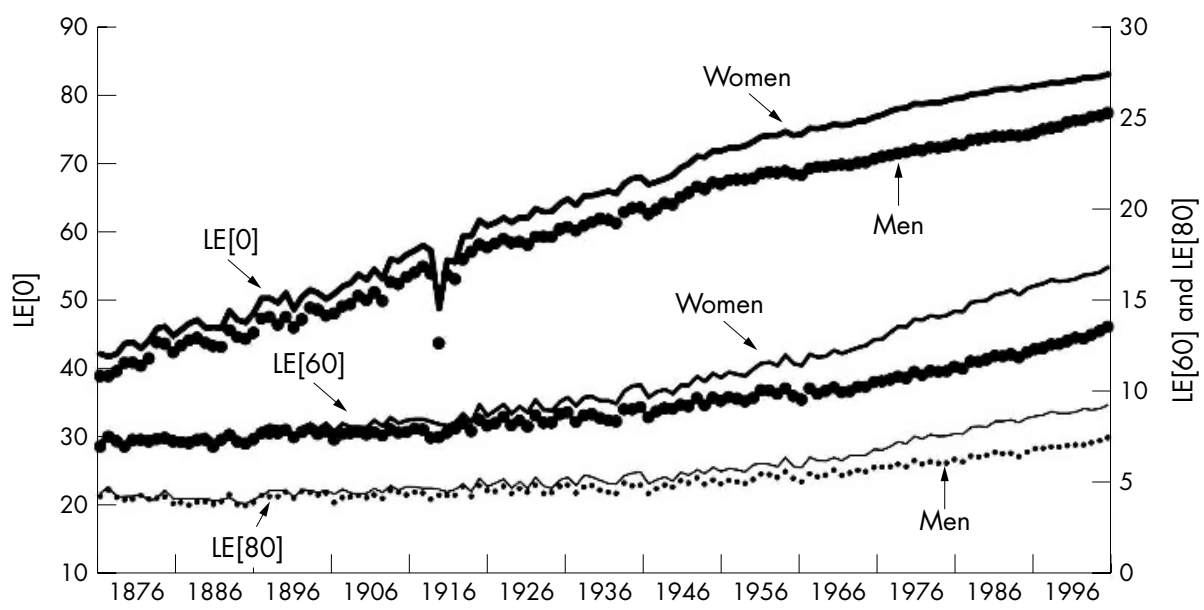

Figure 1 Life expectancy at birth $\left(\mathrm{LE}_{[0]}\right)$, at age $60\left(\mathrm{LE}_{[60]}\right)$ and at age 80 $\left(\mathrm{LE}_{[80]}\right)$, by gender. Switzerland, 18762000 .

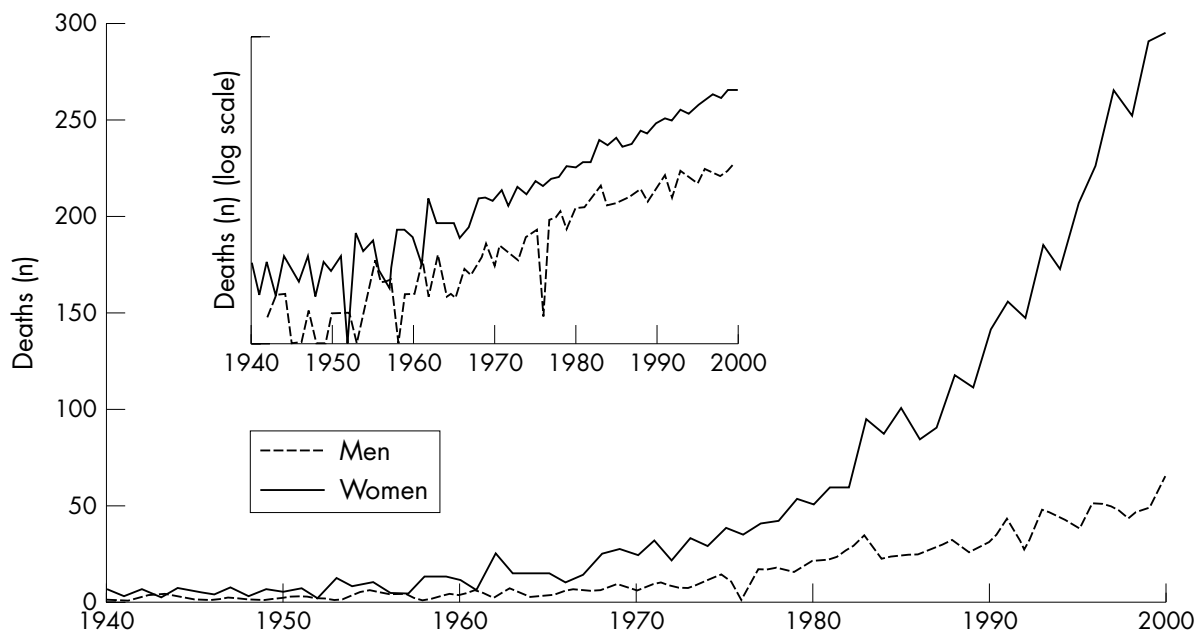

Figure 2 Number of deaths at age 100 and over, by gender. Switzerland, 1940-2000 (Insert shows the same data, with the number of deaths on a log scale).

men and by $96 \%$ for women. The figure suggests two periods characterised with different rates of increase: the annual increase of $\mathrm{LE}_{[0]}$ was four or five months per year before 1950 ( 0.37 year for men, 0.39 year for women), followed by a second period marked by a slower rate of increase (only three months per year after 1950: 0.22 year for men and 0.24 year for women).

The centenarian doubling time is the number of years needed to double the number of people aged 100 or more in a community; it is calculated from the annual increase in the absolute number of centenarians.

Figure 1 also shows the trends in life expectancy at age 60 $\left(\mathrm{LE}_{[60]}\right)$ and at age $80\left(\mathrm{LE}_{[80]}\right)$. Over the entire period, $\mathrm{LE}_{[60]}$ increased by $81 \%$ (men) and $109 \%$ (women). For $\mathrm{LE}_{[80]}$, corresponding figures are $73 \%$ and $106 \%$, respectively. As for $\mathrm{LE}_{[0]}$, the rate of increase differs over the period. Until 1920, $\mathrm{LE}_{[60]}$ and $\mathrm{LE}_{[80]}$ increase slower than $\mathrm{LE}_{[0]}$, or even fluctuate around the 1876 values. Around the 1950s, in contrast, both

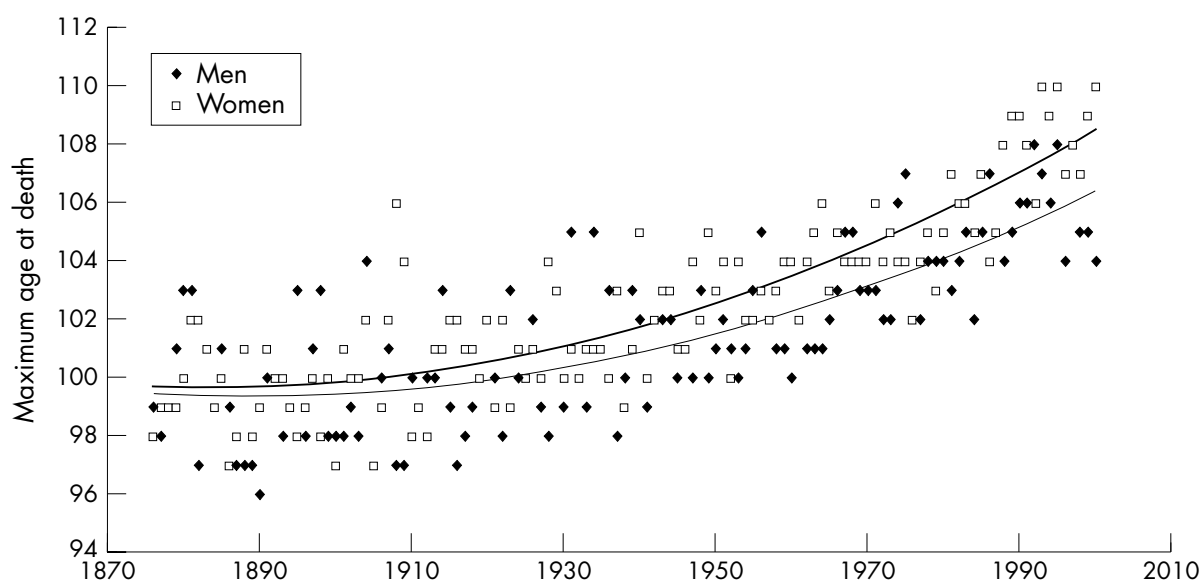

Figure 3 Maximal age at death recorded each year, by gender (solid lines represent the quadratic adjustment of the individual values, bold upper line for women, thin lower line for men). Switzerland, 1876-2001. 


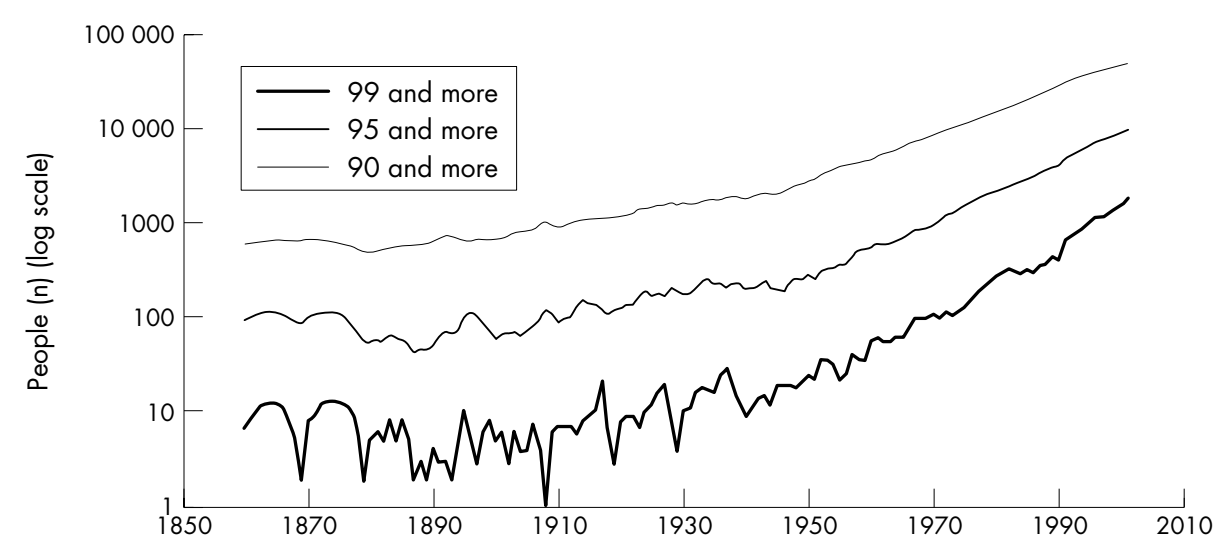

Figure 4 Number of people aged 90 and more, 95 and more, and 99 and more. Switzerland, yearly estimates, 1860-2001.

$\mathrm{LE}_{[60]}$ and $\mathrm{LE}_{[80]}$ increase more rapidly than before, and more rapidly than $\mathrm{LE}_{[0]}$. The change in the rate of increase is more pronounced among women than among men.

An indirect estimation of longevity is to plot the number of deaths of people aged 100 and more, information available since 1940 in Switzerland. This number increased, from less than 10 deaths to 66 (men) and 295 (women) as shown in figure 2. The insert (with a semi-log scale) shows that this increase was roughly constant throughout the period. Despite the large difference between men and women in the absolute number of centenarians, the increase rate is similar across genders. The trend is erratic at the beginning at the period, partly because of the smaller numbers.

Another indirect approach is to look at the yearly maximal age at death-that is, the highest duration of life recorded at a given calendar year. In figure 3, each point represents the maximal ages reached in each gender. The increase is obvious in both genders, with higher values for women than for men (see quadratic adjustment). An acceleration of the increase is visible in the 1940s and 1950s. Mean maximal age at death was about 102 years between 1880 and 1920 (101.7 for men, 102.3 for women). It then reached 104 years between 1920 and 1960 (mean values: 103.7 for men, 104.4 for women), and currently reaches 110 years (mean values from 1961 to 2001: 106.9 for men, 108.5 for women).

Using yearly estimates of the number of people aged 90 and more, figure 4 shows the trend for the period 1860-2001. Three periods can be distinguished: (a) before 1900, a rather constant number of people aged 90 and more around 650, (b) between 1900 and 1945, a steady increase, reaching 2000 persons in 1945, (c) after 1945, a steeper increase, up to 47000 persons in 2000. Thus, the number of people aged 90 and more has been multiplied by 3 between the first and the second period, and multiplied by 25 between the second and the third period. The distribution between age groups has remained steady over the period: there are 10 times more people aged 90 years and more than people over 95 , and 10 times more people over 95 years than people of 99 and more. This can be taken as a rule of thumb valid over the entire period.

An exact enumeration of people aged 100 and more is available only in census years. At the last census ( 1 December 2000), 364 persons were aged exactly 100 years, out of 796 persons aged 100 and more. The 15 point prevalence estimates available from 1860 to 2000 are plotted in figure 5 . The number goes from 10 (1860) to 796 (2000) — that is, a multiplication by 80 in 140 years. The number of centenarians decreases at the end of the 19th century from the 1860 census. Their number remains extremely low during the first decades of the 20th century, with some fluctuation during the period 1930-1950 and a maximum reached in 1940. From 1970 onwards, the number of enumerated centenarians clearly increases.

An obvious determinant of the number of centenarians is the size of the population aged less than 100. The centenarian rate for birth cohort $\left(\mathrm{CR}_{[0]}\right)$ controls this size effect, using the

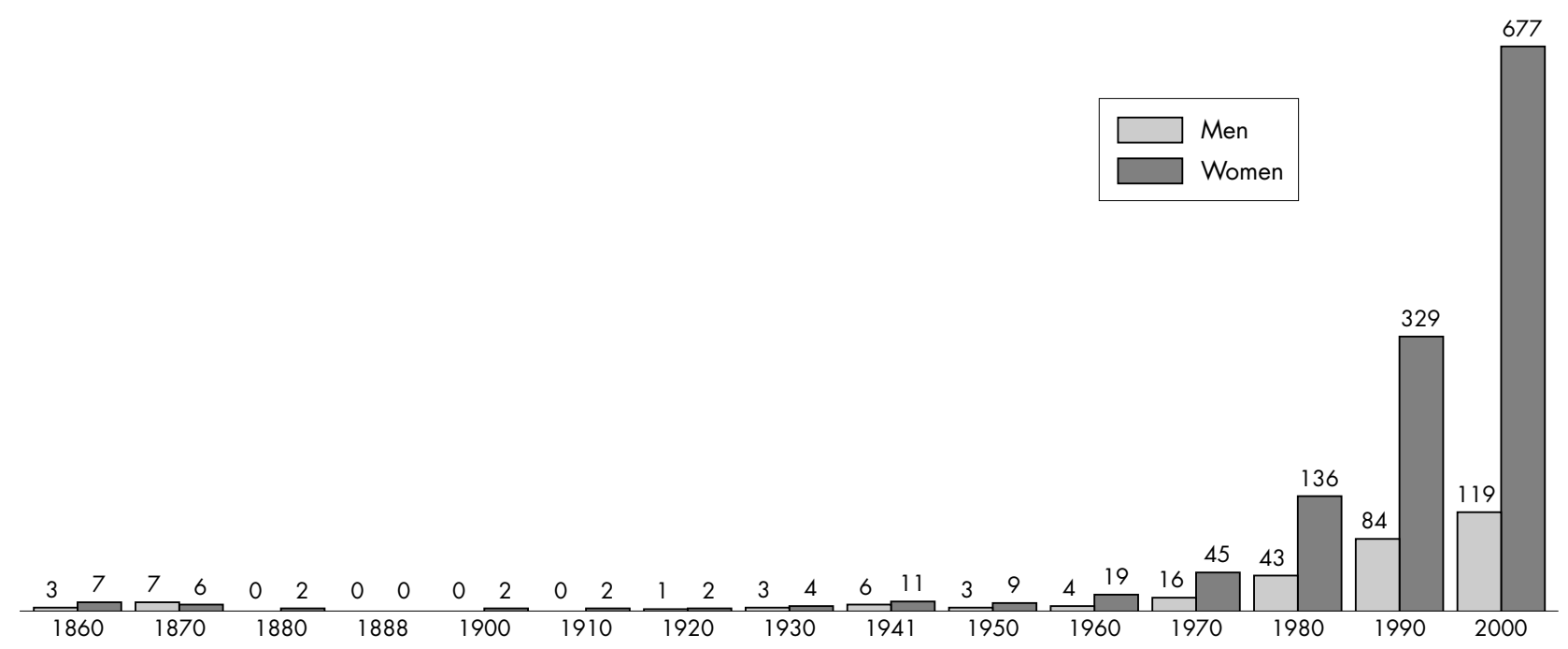

Figure 5 Number of people aged 100 and more. Switzerland, census data, 1860-2000. 
Table 1 Centenarian rates for cohorts at birth $\left(\mathrm{CR}_{[0]}\right)$ and for cohorts at age $60\left(\mathrm{CR}_{[60]}\right)$, by gender. Switzerland, centenarians at census 1960, 1970, 1980, 1990, and 2000

\begin{tabular}{|c|c|c|c|c|c|c|}
\hline & \multicolumn{2}{|l|}{$\mathrm{CR}_{[0]}$} & \multicolumn{2}{|c|}{$\mathrm{CR}_{[60]}$} & \multicolumn{2}{|c|}{ Ratio $\mathrm{CR}_{[60]} / \mathrm{CR}_{[0]}$} \\
\hline & Men & Women & Men & Women & Men & Women \\
\hline 1960 & 0.8 & 2.2 & 2.2 & 4.8 & 2.8 & 2.2 \\
\hline 1970 & 2.2 & 6.5 & 5.7 & 13.7 & 2.6 & 2.1 \\
\hline 1980 & 5.6 & 16.3 & 13.5 & 32.1 & 2.4 & 2.0 \\
\hline 1990 & 6.2 & 38.2 & 13.0 & 62.6 & 2.1 & 1.6 \\
\hline 2000 & 11.6 & 66.8 & 21.6 & 99.3 & 1.9 & 1.5 \\
\hline
\end{tabular}

The centenarian rate is the number of survivors aged 100 at a given date divided by the size of the corresponding cohort at a given age, for example, at birth one century before $\left(\mathrm{CR}_{[0]}\right)$ or at age 60 years, 40 years before $\left(\mathrm{CR}_{[60]}\right)$.

Table 2 Number of centenarians and centenarian doubling time, by gender. Switzerland, birth cohorts $1870,1880,1890$, and 1900, standard $=1870$

\begin{tabular}{llcc}
\hline & & Men & Women \\
\hline Number of centenarians at census, & 1970 & 8.0 & 19.8 \\
standardised for birth cohort size & 1980 & 23.3 & 63.1 \\
(standard = 1870) & 1990 & 23.3 & 145.0 \\
& 2000 & 53.5 & 294.5 \\
Centenarian doubling time & $1970-1980$ & 6.5 & 6.0 \\
& $1980-1990$ & - & 8.3 \\
& $1990-2000$ & 8.4 & 9.8 \\
\hline
\end{tabular}

ratio of the number of people aged exactly 100 at a given census divided by the number of births recorded 100 years before this census. $\mathrm{CR}_{[0]}$ can be estimated for the past four censuses in Switzerland, corresponding to four birth cohorts (1860, 1870, 1890, and 1900). A similar indicator is the $\mathrm{CR}_{[60]}$ - that is, the rates of centenarians in the cohort of people aged 60 years.
Table 1 shows the centenarian rates, $\mathrm{CR}_{[0]}$ and $\mathrm{CR}_{[60]}$, increase in both genders. Overall, $\mathrm{CR}_{[0]}$ goes from 1.5 centenarians per 10000 births in 1860 ( 0.8 for men, 2.2 for women) to 38.6 in 1900 (11.6 for men, 66.8 for women). The increase is more pronounced among women. Values are higher for $\mathrm{CR}_{[60]}$ (as expected because of the selective effect of mortality before the age of 60), but follow a similar pattern: $\mathrm{CR}_{[60]}$ increases from 2 to 22 for men and from 5 to 100 for women. A slowing down in the increase of CRs is apparent since the 1980s.

The advantage of women over men is striking: female $\mathrm{CR}_{[0]}$ is always larger than male $\mathrm{CR}_{[60]}$, and this advantage increases over the period. Table 1 also shows that the ratio $\mathrm{CR}_{[60]} / \mathrm{CR}_{[0]}$ is always larger among men than among women, suggesting that the selective effect of early mortality is stronger for men than for women. A further point to note is that, in both genders, the ratio $\mathrm{CR}_{[60]} / \mathrm{CR}_{[0]}$ decreases over the period: this is compatible with a stronger decrease in mortality after the age of 60 than before this age.

Table 2 shows the evolution of the number of centenarians taking the 1870 birth cohort as standard. The increase is evident in both genders, but is more pronounced for women.

Table 3 Determinants of the increase in the number of centenarians: cohort size at selected ages, probability of survival (\%) between selected ages, and increase factors. Switzerland, 1870 and 1900

\begin{tabular}{|c|c|c|c|c|c|c|}
\hline & \multicolumn{3}{|l|}{ Men } & \multicolumn{3}{|c|}{ Women } \\
\hline & 1870 & 1900 & factor & 1870 & 1900 & factor \\
\hline \multicolumn{7}{|l|}{ Cohort sizes } \\
\hline At birth & 40570 & 48223 & 1.2 & 38638 & 46093 & 1.2 \\
\hline at 80 & 4086 & 9065 & 2.2 & 6185 & 17304 & 2.8 \\
\hline at 100 & 9 & 53 & 6.2 & 23 & 294 & 12.5 \\
\hline \multicolumn{7}{|l|}{ Survival in \% } \\
\hline From birth to 80 & 10.1 & 18.8 & 1.9 & 16 & 37.5 & 2.3 \\
\hline From 80 to 100 & 0.21 & 0.58 & 2.8 & 0.38 & 1.7 & 4.5 \\
\hline
\end{tabular}

Table 4 Mortality of people aged 100. Switzerland, vital statistics and census data, 1960-2000

\begin{tabular}{|c|c|c|c|c|c|c|}
\hline & \multicolumn{3}{|l|}{ Men } & \multicolumn{3}{|l|}{ Women } \\
\hline & $\begin{array}{l}\text { Number deaths } \\
\text { at age } 100 \\
\text { during the } \\
\text { census year }\end{array}$ & $\begin{array}{l}\text { Number aged } \\
100 \text { at census }\end{array}$ & $\begin{array}{l}\text { Mortality } \\
\text { estimates } \\
(\%)\end{array}$ & $\begin{array}{l}\text { Number deaths } \\
\text { at age } 100 \\
\text { during the } \\
\text { census year }\end{array}$ & $\begin{array}{l}\text { Number aged } \\
100 \text { at census }\end{array}$ & $\begin{array}{l}\text { Mortality } \\
\text { estimates } \\
(\%)\end{array}$ \\
\hline 1960 & 3 & 3 & 100.0 & 6 & 8 & 75.0 \\
\hline 1970 & 4 & 9 & 44.4 & 17 & 25 & 68.0 \\
\hline 1980 & 8 & 24 & 33.3 & 31 & 67 & 46.3 \\
\hline 1990 & 13 & 25 & 52.0 & 56 & 147 & 38.1 \\
\hline 2000 & 33 & 56 & 58.9 & 112 & 308 & 36.4 \\
\hline
\end{tabular}




\section{Key points}

- Worldwide, life expectancy of men at birth has increased from 25 to 65 years over the past two centuries

- In some countries, female life expectancy has increased by three months per year for 160 years

- As a consequence, the number of centenarians is rapidly increasing, doubling every 10 years since the 1960s

- A key period in Switzerland is around 1950, when mortality after age 60 started to decrease rapidly and consistently

- The increase in centenarians is similar across genders despite a large difference in absolute numbers between men and women

- The decline in Swiss mortality after 80 explains more than half of this increase

However, the centenarian doubling time (CDT) decreases among women, from six years in the 1970s (that is, six years were necessary to double the absolute number of centenarians) to 10 years currently. The small numbers confuses the situation among men.

Table 3 shows an attempt to disentangle the determinants of the increase in centenarians from the cohort 1870 to the cohort 1900. For women, the number of centenarians has increased by a factor of 12.5. Part of this increase is explained by the increase in the cohort size by a factor of 1.2. The remaining effect is attributable to a mortality decline, which is broken down into (a) an effect of early mortality (between birth and age 80), and (b) an effect of late mortality (between 80 and 100). For example, among women, the improvement in early mortality is estimated by the increase in survival between birth and age 80 (by a factor of 2.3), and the improvement in late mortality by the increase in survival between 80 and 100 (by a factor of 4.5). The multiplicative model for the increase in centenarians thus includes three factors of change (size of the birth cohort and two elements of mortality) to determine the increase in female centenarians $(1.2 \times 2.3 \times 4.5=12.5)$. According to this, the decline in mortality after 80 explains more than half of this increase, and the decline in mortality from birth to 80 explains another third.

The same proportions can be found among men, as shown in the table 3.

Table 4 shows the trend in mortality among centenarians during the past 40 years, as estimated by the number of deaths occurring around the census. There is a clear decline from $75 \%$ to $36 \%$ among women. The trend is less obvious for men, probably related to the smaller number involved.

\section{DISCUSSION}

This paper explores the rapid emergence of a new population in Switzerland, the oldest old, and gives some clues to the mechanism underlying this increase. It shows that the emergence of the extremely old population is mainly related to the decrease in mortality at old age, that the critical period for change occurred in the 1950s, and that women are well in advance of men.

This study uses routine demographic data. Sophisticated data on health status, disease, life trajectories, etc, are not routinely available over long periods in most countries, including Switzerland. Even cause of death is notoriously difficult to use for the epidemiology of old and very old
Policy implications

- Trends in longevity should be monitored to reach a better understanding of underlying mechanisms

- Suggested indicators to monitor longevity include life expectancy, number of deaths beyond age 100, maximal age reported at death, centenarian doubling time, centenarian rate

populations, not to mention the problem of secular trend in the assessment of cause of death. ${ }^{29-33}$

An astute use of demographic data is therefore indicated. An obvious advantage is that these data have been collected in a standardised manner: this allows for comparison over long periods (since 1860 in this study) and across many communities.

Several indicators have been suggested to capture mortality of the oldest old, such as the method of the extinct cohorts, ${ }^{34}{ }^{35}$ the centenarian rate, the centenarian doubling time, ${ }^{10}$ etc. Life expectancy is also used, ${ }^{36}$ but suffers from drawbacks when used in small populations as for centenarians. The best approach is probably to use several indicators and to identify convergence between them.

Centenarian rate deserves a special comment: it is an attractive tool to compare populations over time and across communities, controlling for the size of birth cohorts, infant mortality, past migrations, and policies of naturalisation. A major problem in Switzerland is the effect of migration affecting the cohort since its inception: naturalisation is a major part of population change. For example, from 1971 to 2001, 240000 persons became Swiss-that is, about 10\% of the total number of births during this period ( $12.5 \%$ of births of Swiss citizens and $41.9 \%$ of foreign births). On the other hand, most of those who will become Swiss are born in Switzerland, and $21 \%$ of them are aged 10 when they acquired a Swiss passportt.

The $\mathrm{CR}_{[60]}$ - that is, the ratio of the number of centenarians to the number of the population 40 years before-has been proposed by Caselli to overcome the problem of migration inherent to the use of $\mathrm{CR}_{[0]}$ : the population between 60 and 100 is not likely to migrate and/or to change nationality. In Switzerland, between 1971 and 2001, only $3.5 \%$ of naturalisations occurred at 60 years or later. A further advantage of the $\mathrm{CR}_{[60]}$ is the control of other potential confounders such as infant mortality, which affect the number of centenarians when comparing countries with different infant mortality.

In any case, a condition for the use of demographic indicators is the improvement and maintenance of data quality, especially that related to the elderly population. Extreme age was unreliable in Switzerland until the 1950s, despite the fact that the maintenance of demographic statistics was set as a federal task more than one century ago (the first nationwide census was carried out in 1860, and vital statistics have been collected since the 1870s). Before 1950, the number of centenarians fluctuates erratically, with even a decline between 1860 and 1940. A similar pattern has been noted in Denmark, ${ }^{37} 38$ with a decreasing trend in centenarians in the last decades of the19th century and in the first decades of the 20th century.

Huge improvements in obtaining demographic data have been made in low mortality countries. However, there are still

†Unlike other countries, being born in Switzerland does not imply Swiss citizenship: a formal request has to be made, and accepted by the federal, cantonal, and communal authorities. As a general rule, residence of at least 12 years is a pre-condition. 
difficulties with the enumeration of aged people and their deaths. Recent findings suggest that the number of oldest old is still biased, perhaps with a gender specific bias. ${ }^{39}$

Apart from these points on data and indicators, some observations deserve specific remarks. The first is related to the increase in the number of centenarians. All indicators converge to suggest that the increase in Switzerland has been strong, one of the strongest rates, together with Japan. This corresponds to an increase in longevity, which has been observed in other countries, ${ }^{2}$ but is particularly visible in Switzerland because of the lack of major disasters during the past 150 years. This pattern of increase suggests that a combination of factors (rather than a single factor) played a part, related to sanitation, income, nutrition, and health care. ${ }^{1}$

On the other hand, there is a clear change in the 1950s, with the decline in mortality becoming more rapid. A similar pattern has been observed in Sweden, ${ }^{40}$ with a pace of increase in longevity of 0.44 years per decade before 1969, accelerating to 1.11 years per decade after that date. The 1950s have been found crucial for the emergence of the oldest old in France (Robine, personal communication). Causal explanation can be related either to contemporary improvement during the 1950s (that is, sanitary and socioeconomic environment directly benefiting the old and the oldest old such as antibiotic treatment for pneumonia, pension scheme for the elderly population, etc), or to past improvements in the corresponding birth cohorts. It is difficult to disentangle these factors within the scope of this paper. The improvement in the socioeconomic situation in Switzerland has been massive since the second world war, with direct benefits for old persons. A study in Sweden for the years 1861 to $1999^{41}$ suggests that mortality among people aged $90-94$ is directly correlated with general wealth as measured by manufacturing wages. It is less easy to identify similar improvements for the history of birth cohorts born in 1890 and after (that is, those aged 60 and over in the 1950s): these were confronted with two wars (of less dramatic impact in Switzerland than elsewhere, but still a challenge) and a pronounced economic crisis in the 1930s.

Another important point is that, in both genders, almost two thirds of the increase in the number of centenarians is attributable to the improvement of mortality after 80; one third to improvement of mortality before 80 , and less than $10 \%$ being attributable to the size of the birth cohorts. A recent study in Sweden also shows that more than $70 \%$ of the increase in maximum age at death from 1861 to 1999 is attributable to reductions in death rates above age $70 .^{40}$

A last point is the slowing down of the mortality decline at older age, as suggested by the increase in the centenarian doubling rime (in women). This is worth mentioning because several countries still enjoy a strong decline in mortality at old age, ${ }^{42-47}$ notably Japan and France. ${ }^{910}$ The deceleration observed in Switzerland may be more in line with what has been reported in Denmark, England and Wales, Norway (with a stabilisation or even an increase in mortality at old age between 1986/90 and 1991/9448) and the Netherlands (with $\mathrm{LE}_{[60]}$ increasing in the 1970s and 1980s, whereas $\mathrm{LE}_{\text {[85] }}$ declining since 1980/84 among men and since 1985/89 among women ${ }^{36}$ ).

Possible explanations for this slowing down include epidemics of influenza, concomitant aspects of healthcare delivery (for example, the development of euthanasia), or lifestyle changes in adulthood or infancy (for example, change in the prevalence of smoking). More analyses are needed to relate secular changes in these possible determinants with the slowing down observed here. Another possible cause of this slowing down is the increasing frailty of this population: although the concept is still elusive, the idea that decreasing mortality among the youngest old may have produced a frailer oldest old population is attractive.$^{49}$ Finally, another explanation could be related to rectangularisation: because this decrease is observed in countries with very extended life expectancy, the slowing down of mortality at extreme age is also compatible with early signs of rectangularisation of the survival curve. ${ }^{50}{ }^{51}$ However, more studies, particularly comparative studies, on the emergence of extremely old populations in low mortality countries are required.

\section{ACKNOWLEDGEMENTS}

We thank the staff of the Swiss Federal Office of Statistics for their kind cooperation, particularly Stéphane Cotter, head of the Section of Population Evolution. The authors also thank anonymous reviewers for their careful comments on the manuscript.

\section{Authors' affiliations}

J-M Robine, Group "Health and Demography", University of Montpellier 1, France

F Paccaud, Institute for Social and Preventive Medicine, Faculty of Biology and Medicine of Lausanne, Switzerland

Funding: none.

Conflicts of interest: none declared.

\section{REFERENCES}

1 Riley J. Rising life expectancy: a global history. Cambridge: Cambridge University Press, 2001

2 Oeppen J, Vaupel JW. Broken limits to life expectancy. Science 2002;296:1029-31.

3 Heiniger M, Wanders AC. Portrait démographique de la Suisse. Berne: Office fédéral de la statistique, 2002.

4 Vaupel JW, Jeune B. The emergence and proliferation of centenarians. In: Jeune B, Vaupel JW, eds. Exceptional longevity: from prehistory to the present. Odense: Odense University Press, 1995

5 Krach CA, Velkoff VA. Centenarians in the United States. Washington, DC: US Department of Health and Human Services, 1999.

6 Poulain M. Chambre D, Foulon M. Survival among Belgian centenarians (1870-1894 cohorts). Population 2001;13:117-38.

7 Thatcher AR. The demography of centenarians in England and Wales. Population 2001;13:139-56.

8 Ministry of Health, Labor and Welfare. Life tables for Japan 2002. Tokyo: Ministry of Health, Labor and Welfare (Statistics and Information Department), 2003.

9 Robine JM, Saito Y. Survival beyond age 100: the case of Japan. Pop Dev Rev 2003;29(suppl):208-28.

10 Robine JM, Saito Y, Jagger C. The emergence of extremely old people: the case of Japan. Exp Gerontol 2003;38:735-9.

11 Ebrahim S. Public health implications of ageing. J Epidemiol Community Health 1997;51:469-72

12 Palacios R. The future of global ageing. Int J Epidemiol 2002;31:786-91.

13 Bonneux L, Barendregt JJ, Van der Maas PJ. The expiry date of man: a synthesis of evolutionary biology and public health. J Epidemiol Community Health 1998;52:619-23.

14 Vaupel JW, Carey JR, Christensen K, et al. Biodemographic trajectories of longevity. Science 1998;280:855-60.

15 Wilmoth JR. The future of human longevity: a demographer's perspective. Science 1998;280:395-7.

16 Horiuchi S. Greater lifetime expectations. Nature 2000;405:744-5.

17 Olshansky SJ, Carnes B, Désesquelles A. Prospects for human longevity. Science $2001 ; 291: 1491-2$.

18 Wimoth JR. How long can we live? A review essay. Pop Dev Rev 2001;27:791-800.

19 Robine JM, Vaupel JW. Emergence of supercentenarians in low-mortality countries. North Am Actuarial J 2002;6:54-63.

20 Robine JM. Life course, environmental change, and life span. Pop Develop Rev 2003;29(suppl):229-38

21 Baranzini C. Tableau du mouvement naturel de la population, depuis 1870. Berne: Office fédéral de la statistique, 1998.

22 Heiniger M, Daout V. Portrait démographique de la Suisse 2001. Berne: Office fédéral de la statistique, 2001.

23 Calot G. Deux siècles d'histoire démographique suisse. Berne: Office fédéral de la statistique, 1998.

24 Wanner P. Tables de mortalité pour la Suisse 1988/1993. Berne: Office fédéral de la statistique, 1996

25 Mentonnex J, Wanner P. Tables de mortalité longitudinales pour la Suisse, Génération 1880-1990. Berne: Office fédéral de la statistique, 1998.

26 Ammon CE. Spanish flu epidemic in 1918 in Geneva, Switzerland. Eur Surveill 2002;7:190-2.

27 Nussbaum W. The influenza epidemic of 1918/1919 in the Swiss army. [In German]. Gesnerus 1982;39:243-59. 
28 Bettex M. La grippe de 1918 à La Tour-de-Peilz. Rev Med Suisse Romande 1967;87:835-6.

29 Smith DWE. Human longevity. New York, NY: Oxford University Press, 1993

30 D'Amico M, Agozzino E, Biagino A, et al. Ill-defined and multiple causes on death certificates - a study of misclassification in mortality statistics. Eur J Epidemiol 1999;15:141-8.

31 Lloyd-Jones DM, Martin DO, Larson MG, et al. Accuracy of death certificates for coding coronary heart disease as the cause of death. Ann Intern Med 1998; 129:1020-6.

32 Fogata ML, Naik PN, Goldberg TH. Causes of death in the very old. J Am Geriatr Soc 1996;44:1412-13.

33 Kohn RR. Cause of death in very old people. JAMA 1982;247:2793-7.

34 Vincent P. La mortalité des vieillards. Population 1951;6:181-204.

35 Manton KG, Vaupel JW. Survival after the Age of 80 in the United States, Sweden, France, England, and Japan. N Engl J Med 1995;333:1232-5.

36 Nusselder WJ, Mackenbach JP. Lack of improvement of life expectancy at advanced ages in the Netherlands. Int J Epidemiol 2000;29:140-8.

37 Jeune B. In search of the first centenarians. In: Jeune B, Vaupel JW, eds. Exceptional longevity: from prehistory to the present. Odense: Odense University Press, 1995

38 Skytthe A, Jeune B. Danish centenarians after 1800. In: Jeune B, Vaupel JW eds. Exceptional longevity: from prehistory to the present. Odense: Odense University Press, 1995

39 Condran GA, Himes $\mathrm{CL}$, Preston SH. Old-age mortality patterns in low mortality countries: an evaluation of population and death data at advanced ages, 1950 to the present. Popul Bull United Nations 1991;30:23-60.

40 Wilmoth JR, Deegan $\amalg$, Lundstro $H$, et al. Increase of maximum life-span in Sweden, 1861-1999. Science 2000;289:2367-8.
41 Catalano R. Economic antecedents of mortality among the very old. Epidemiology 2002;13:133-7.

42 Grundy E. Mortality and morbidity among the old. BMJ 1984;288:663-4.

43 Myers JC Comparative mortality trends among older persons in developed countries. In: Caselli G, Lopez AD, eds. Health and mortality among elderly populations. Oxford, UK: Clarendon Press, 1996:87-111.

44 Vaupel JW, Lundstrom $\mathrm{H}$. The future of mortality at older ages in developed countries. In: Lutz W, ed. The future population of the world: What can we assume today? London, UK: Earthscan Publications, 1994:295-315.

45 Kannisto V, Lauristen J, Thatcher AR, et al. Reductions in mortality at advanced ages: several decades of evidence from 27 countries. Popul Dev Rev 1994;20:793-809.

46 Manton KG. Changing concepts of morbidity and mortality in the elderly population. Milbank Mem Fund Q Health Soc 1982;60:183-244.

47 Rothenberg R, Lentzner HR, Parker RA. Population aging patterns: the expansion of mortality. J Gerontol 1991;46:S66-70.

48 Mamelund S, Borgan J. Kohort-og Periodedodelighet i Norge 1846-1994 [Cohort and Period Mortality in Norway 1846-1994]. Oslo, Norway: OsloKongsvinger, 1996.

49 Vaupel JW, Manton KG, Stallard E. The impact of heterogeneity in individual frailty on the dynamics of mortality. Demography 1979; 16:439-54

50 Paccaud F, Sidoti Pinto C, Marazzi A, et al. Age at death and rectangularisation of the survival curve: trends in Switzerland, 1969-1994. J Epidemiol Community Health 1998;52:412-15.

51 Nusselder WJ, Mackenbach JP. The rectangularization of the survival curve in Netherlands, 1950-1992. Gerontologist 1996;36:773-82. 